\title{
Responsiivisten vuorojen kielioppia
}

Sandra A. Thompson, Barbara A. Fox \& Elizabeth Couper-Kuhlen: Grammar in everyday talk. Building responsive actions. Studies in Interactional Sociolinguistics 31. Cambridge: Cambridge University Press 2015. 341 s. ISBN 978-1-107-03102-9.

Keskustelunanalyyttisessä tutkimuksessa päämääränä on usein selvittää, mitä puhuja tekee käyttämällä tiettyä kielellistä rakennetta tietyssä sekventiaalisessa asemassa. Tarkasteltavana oleva teos Grammar in everyday talk jatkaa tällä linjalla, mutta pyrkii tarjoamaan yksittäisen toimintakontekstin tai kielellisen muodon tarkastelun sijaan yleiskuvan vastausvuoron tuottamisesta amerikanenglannissa. Teos tarkastelee vastauksen tuottamista neljään erityyppiseen etujäseneen: kysymyssanan sisältävään tiedonhakuun (What time are we leaving? - Seven), tiedonantoon (The May Company are sure having a big sale - Are they?), kannanottoon (Track walking is so boring. Even with headphones - It is) ja toimintapyyntöön (Please don't tell Adeline - Oh no I won't say anything). ${ }^{1}$ Etujäseninä näissä sekvensseissä toimii siis ihmisen sosiaalisuuden kannalta keskeisimpiä toimintoja: tiedon välittäminen, mielipiteiden ja kokemusten jakaminen sekä pyytäminen (ks. Tomasello 2008). Teoksella on suomalaista lukijaa ilahduttava yhteys: yksi teoksen kolmesta tekijästä, Elizabeth Couper-Kuhlen, on toiminut FiDiPro-professorina Helsingin yliopistossa.

Teoksen tarkastelun lähtökohtana on Schegloffin (1996) esittämän "asemakieliopin" (positionally sensitive grammar) käsite eli ajatus siitä, että kielellisten toimintojen muotoilua ohjaa niiden sekventiaa-

1. Kaikki antamani esimerkit ovat peräisin teoksesta. linen asema. Näin ollen esimerkiksi kysymykseen Who won the feature? annettu lausekevastaus $A l$ voidaan ymmärtää vastauksen perusmuodoksi kyseisessä sekventiaalisessa asemassa, kun taas mahdolliset laajemmat vastaukset (esim. "Al won") ilmentäisivät jotakin erityiskäyttöä. Grammar in everyday talk -teoksen tavoitteeksi ilmaistaan juuri sen selvittäminen, mikä on vastauksen perusmuoto tarkasteluun valituissa sekvensseissä ja mitä erityiskäyttöä muun tyyppiset vastaukset näissä sekvensseissä ilmentävät (s. 9). Analyysissä erotetaan kuusi eri vastaustyyppiä: 1) partikkelivastaukset, joihin lasketaan kuuluviksi myös leksikaalistuneet kiteytymät (esim. my gosh), 2) lausekevastaukset, 3) minimaaliset lausevastaukset, jotka sisältävät vain pronominin ja apuverbin, 4) laajat lausevastaukset, 5) asteittavat lausevastaukset (graded clausal), jotka joko vahvistavat (upgrade) tai heikentävät (downgrade) etujäsenessä esitettyä arviota, ja 6) etujäsenen muodosta riippumattomat lausevastaukset (unrelated clausal). Tekijöiden tarkoituksena on osoittaa, että eri toimintakonteksteissa voi olla erilaisia vastauksen perusmuotoja niin, että yhdessä kontekstissa partikkeli on vastauksen perusmuoto, kun taas toisessa se voi olla etujäsenen muodosta riippumaton lausevastaus.

Ennen kuin tekijät tarttuvat valitsemiinsa toimintakonteksteihin ja vastausten muotoihin niissä, he pohtivat teoksen johdantoluvussa responsiivisen eli vastauksena toimivan vuoron määrittelyä. Korjausaloitteet ja puhujaa jatkamaan kehottavat minimipalautteet rajautuvat pois responsiivisten vuorojen joukosta, sillä kumpikaan niistä ei ole responsiivinen yhdelle spesifille toimintatyypille vaan niitä voidaan käyttää monentyyppisissä konteksteissa. Responsiivisen vuoron kri- 
teeriin kuuluu siis teoksen mukaan se, että vuoro on sekvenssisidonnainen ( $s e$ quence spesific) eli vastaa tietynlaiseen etujäsenenä toimivan vuoroon. Tämän lisäksi responsiivinen vuoro ottaa tavalla tai toisella käsittelyyn etujäsenenä toimivan vuoron välittämän toiminnon. Teoksessa ei kuitenkaan oteta kantaa esimerkiksi siihen, onko vastauksen tuottamiselle luotu selvä odotus ja sekventiaalinen paikka vai tuottaako puhuja vastauksen omasta aloitteestaan. Tästä syystä avoimeksi jää, voiko vuoroa pitää responsiivisen vuoron rajauksen mukaisesti sekvenssisidonnaisena, jos vuoron tuottamiselle ei ole luotu selvästi odotusta. Toisaalta tekijät joutuvat myöhemmin pohtimaan rajankäyntiä tiedonannon jälkeisen korjausaloitteen (esim. Of course it came out fine - It came out negative) ja tiedonannon vastaanottavan vuoron (They're good for you - They're good for you?) välillä. Tässä pohdinnassa he päätyvät esittämään jatkumon eniten korjausaloitteen kaltaisen vuoron ja selvimmin tiedonannon vastaanottavan vuoron välillä.

\section{Kysymyssanan sisältävään tiedonhakuun vastaaminen}

Teoksen ensimmäinen analyysiluku (luku 2) käsittelee kysymyssanan sisältäviä tiedonhakuja ja niihin vastaamista. Tässä asemassa vastauksena voidaan käyttää esitellyistä kuudesta vastaustyypistä lausekemuotoisia vastauksia (When's the next election? - Two thousand four), laajoja lausevastauksia (Who'd you just call? - Oh I just called the store) ja etujäsenen muodosta riippumattomia lausevastauksia (Who'd they trade? - Well y'know remember how we were talking about how they traded that second round for a first round next year). Sen sijaan partikkelivastauksia, minimaalisia lausevastauksia tai asteittavia lausevastauksia ei amerikanenglannissa tavata tässä toimintakontekstissa.
Tekijöiden ensimmäinen oivallus on jakaa kysymyssanan sisältävät tiedonhaut kahteen tyyppiin eli tarkennusta hakeviin kysymyksiin (spesifying questions) ja kerrontaa hakeviin kysymyksiin (telling questions) sekä tarkastella vastauksia erikseen näissä luokissa. He osoittavat, että lausekevastaus (esim. Two thousand and four) on vastauksen perusmuoto tarkennusta hakevaan kysymykseen, sillä se käsittelee kysymystä ongelmattomana. Mitä etäämmälle lausekevastauksesta siirrytään ja mitä vähemmän vastaus kierrättää kysymyksessä käytettyjä resursseja, sitä suurempia ongelmia puhuja implikoi vastaukseen liittyvän. Esimerkiksi laajat lausevastaukset tarkennusta hakeviin tiedonhakuihin ovat tyypillisesti viivästyneitä ja niitä edeltää usein partikkeli tai partikkeliketju, joka implikoi ongelmaa, kun taas etujäsenen muodosta riippumaton lausevastaus vastustaa (resist) kysymyksen muotoilua ja sen implikaatioita (Wow how big is it? - Well you have this- I mean the device itself is very small). Sen sijaan kerrontaa hakevaan kysymykseen vastatessa monilauseiset vastaukset ovat perusmuoto, joka ei implikoi ongelmaa, toisin kuin suppeammat lauseja lausekevastaukset. Esimerkiksi kerrontaa hakevan kysymyksen esittäjä voi käsitellä lausevastausta (esim. What's the story with the sheep? - Pam likes sheep) riittämättömänä hakemalla lisäselitystä annetulle vastaukselle.

\section{Tiedonantoihin vastaaminen}

Tiedonantoa käytetään teoksessa yläkäsitteenä, joka kattaa muun muassa uutisten ja kuulumisten kertomisen. Tiedonanto voidaan antaa osana oma-aloitteista kerrontaa tai vastauksena kysymykseen, joten tiedonantoon vastaaminen on sekventiaalisesti joko toisen tai kolmannen position toiminto (tiedonanto-vastaus; kysymystiedonanto-vastaus). Lisäksi tiedonanto voidaan "kaivaa esiin" (retrieve) sellaisesta 
toisen puhujan vuorosta, jonka pääasiallinen tehtävä ei ole tiedottaminen. Analyysiluku tiedonantoihin vastaamisesta (luku 3) on teoksen laajin, lähes satasivuinen, ja yksityiskohtaisin. Nostan siitä esiin joitakin keskeisiä ja kiinnostavina pitämiäni havaintoja ja väittämiä.

Luvun keskeisin havainto kohdistuu prosodiaan: vastausvuorot, joiden sävelkulku laskee loppua kohti, implikoivat vastaajan tietävän ja ymmärtävän mitä tiedonanto koskee. Laskeva sävelkulku myös ohjaa sekvenssiä kohti sulkeutumista. Sen sijaan vastausvuorot, joiden sävelkulku on nouseva, implikoivat sekvenssille jatkoa ja sitä, että vastaaja kaipaa tiedonannon kertojalta vielä jotakin muuta, esimerkiksi varmennusta.

Kaikkia teoksessa esiteltyjä vastaustyyppejä paitsi asteittavia lauseita (graded clausal) tavataan vastauksena tiedonantoon. Yleisin vastaustyyppi amerikanenglannissa on kuitenkin yksittäinen partikkeli, kuten $o h$. Tekijät käsittelevät yksityiskohtaisesti sen tuottamista ja esittävät vakuuttavasti, että partikkelin oma prosodinen asu (esim. ensin nouseva ja sitten laskeva sävelkulku tai nariseva ääni) ja sen lisäksi ennen kaikkea partikkelin tuottamisen ajankohta suhteessa sitä edeltävään tiedonantoon ovat tärkeitä. Puhuja voi ilmaista esimerkiksi mielenkiintoa ja yllättymistä tuottamalla partikkelin korostuneella prosodialla eli korkeammalla äänellä ja sävelkulun laajemmalla vaihteluvälillä kuin mitä tiedonannossa käytettiin. Partikkelin tuottaminen matalammalla äänellä ja sävelkulun pienempi vaihteluväli sen sijaan voivat välittää empatiaa tai sympatiaa. Muita käsiteltyjä partikkelivastauksia ovat esimerkiksi Really? ja Wow.

Analyysiluku käsittelee myös leksikaalistuneita kiteymiä (prefabs) kuten oh really, you're kidding ja I'll be darned partikkeleina. Niiden analysoidaan yhdistyvän yksittäisiin partikkeleihin kuten oh siten, että ne kaikki sijoittavat tiedon- antoon vastaajan jollekin kohtaa tietämättömän ja tietävän vastaanottajaposition jatkumoa. Samaan tapaan käsitellään yhtenä ryhmänä tiedonantoihin esitettyjä lausekevastauksia (esim. Ice?, In China City?, Leaving for good?). Niitä yhdistää se, että jokin osa tiedonannosta nostetaan tarkastelun kohteeksi, ja erottelevana tekijänä käsitellään lähinnä prosodiaa, jonka päälinja kulkee laskevan ja nousevan sävelkulun välillä. Partikkeli- ja lausekevastausten analyysi on osuvaa, mutta jättää lukijalle avoimeksi kysymyksen, olisiko esimerkiksi erilaisten syntaktisten kiteymien välille hahmoteltavissa funktionaalisia eroja hienojakoisemman analyysin kautta. Tällaisesta toistensa kaltaisten syntaktisten rakenteiden analyysistä ja funktionaalisten erojen esittämisestä niiden välillä on monia fennistisiä esimerkkejä (esim. Hakulinen \& Sorjonen 2009; Niemi 2013; Koivisto 2015, 2016).

Tiedonantoja koskevan analyysiluvun lopuksi tekijät esittävät yleistyksen tiedonantotyypin ja vastauksen suhteesta: Jos tiedonanto tarjotaan oma-aloitteisesti ja se esittelee uuden puheenaiheen, siihen vastataan yleensä lauseella, sillä lausemuotoinen vastaus rohkaisee laajentamaan sekvenssiä. Jos tiedonanto kuitenkin tarjotaan vastauksessa kysymykseen, tiedonanto otetaan vastaan yleensä partikkelilla (esim. Oh; I'll be darned) ja sekvenssiä ohjataan kohti päätöstä. Näin teoksessa esitetään tarkennus aiemmassa kirjallisuudessa (Jefferson 1981; Heritage 1984) esitettyyn erontekoon uutisen vastaanottojen (news receipts) ja topikalisoijien (newsmarks) välillä.

\section{Kannanottoihin vastaaminen}

Teoksen neljäs analyysiluku koskee kannanottoja. Se sisältää nähdäkseni eniten aiempaa keskustelunanalyyttistä kirjallisuutta uudistavaa sisältöä. Luvussa käsitellään toisia kannanottoja eli evaluaation esittäviä responsseja toisen puhujan esit- 
tämään ensimmäiseen kannanottoon (vrt. Pomerantz 1984) sekä laajempien kerrontajaksojen vastaanottamista kannanotolla. Esittelen tässä kuitenkin vain samanmielisyyttä ilmentävien toisten kannanottojen analyysiä. Ensimmäiseen kannanottoon vastaavalla amerikanenglannin puhujalla on käytettävissään neljä kuudesta vastaustyypistä eli lausekevastaus (esim. Awfully nice little person), minimaalinen lausevastaus (esim. It is), laaja lausevastaus (esim. It is cool) sekä asteittava lausevastaus (esim. Oh it's gorgeous). Aiemmassa kirjallisuudessa toisena kannanottona käsiteltyjä partikkelivuoroja kuten Wow ei teoksessa ymmärretä kannanotoiksi, sillä niiden ei katsota ilmaisevan selvää positiivista tai negatiivista orientaatiota (vrt. Goodwin \& Goodwin 1992); partikkelivastaus käsittelee kannanottoa ennemminkin tiedonantona (luku 3).

Tekijät nostavat toisia kannanottoja koskevan analyysin keskiöön keskustelijoiden käymän implisiittisen neuvottelun agentiivisuudesta eli siitä tavasta ja asteesta, jolla puhuja on sitoutunut tiettyyn puhetoimintoon. Kannanottosekvensseissä nähdään tavoitteeksi saavuttaa sitoutumisen symmetria (symmetry of commitment, Enfield 2011), keskustelijoiden välinen yhtäläinen sitoutuminen ensimmäisessä kannanotossa esitettyyn arvioon. Tähän liittyvä kiinnostava väite on se, että minimaalinen lausevastaus, kuten

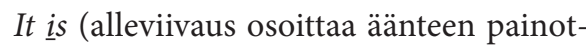
tamista), implikoi puhujansa keskustelukumppania vähäisempää sitoutumista ensimmäiseen kannanottoon ja vastauksen tuottamisen ongelmallisuutta. Sitoutumisen symmetriaa ei siis saavuteta. Esitetty näkemys on osin ristiriidassa aiemman kirjallisuuden (Stivers 2005) kanssa, mutta sopii Pomerantzin (1984) esittämään ajatukseen: saman arvion toistaminen (same evaluation) voi enteillä erimielisyyttä (ks. myös Tainio 1996).

Siinä missä minimaalinen lausevastaus ilmaisee analyysin mukaan vähäistä sitoutumista kannanottoon, laaja lausevastaus (esim. That is cool ja It is very warm) ilmaisee yleensä ongelmatonta samanmielisyyttä ja suurempaa sitoutumista kannanottoon. Kierrättämällä vastauksessaan ensimmäisen kannanoton arvioivaa ilmausta toinen kannanottaja voi implikoida episteemistä itsenäisyyttä ja siten vahvempaa agentiivisuutta sekä sitoutumisen symmetriaa. Laaja lausevastaus tuotetaan yleensä korostetulla prosodialla suhteessa ensimmäiseen kannanottoon, eli vastauksen sävelkulun vaihteluala on laajempi. Tämä tukee analyysiä siitä, että puhuja ilmaisee itsenäistä sitoutumista ja samanmielisyyttä (ks. Ogden 2006; Haddington 2006).

Viimeinen vastauksen rakennetyyppi samanmielisyyttä ilmaisevissa toisissa kannanotoissa on asteittava lausevastaus (graded clausal), jossa ensimmäisessä kannanotossa käytetty evaluoiva termi korvataan saman semanttisen alueen vahvemmalla vastineella (esim. It's very pretty - Oh it's gorgeous). Heritagen ja Raymondin (2005) mukaisesti tekijät esittävät, että tällaisten lausevastausten pääasiallinen tehtävä ei oikeastaan ole samanmielisyyden ilmaisu vaan itsenäisen arviointiaseman korostaminen. Asteittavan lausevastauksen tuottaja ei siis ilmaise sitoutumisen symmetriaa, ja tästä syystä tällaisia vastauksia voidaan käyttää konteksteissa, joihin liittyy vuorovaikutustilanteen ongelma. Teoksessa analysoiduista asteittavista lausevastauksista suurin osa esiintyykin konteksteissa, joihin liittyy jokin vuorovaikutuksellinen ongelma.

Kiinnostava toisiin kannanottoihin liittyvä havainto on se, että ne eivät ole kovin yleisiä. Ensimmäisen puhujan täytyy yleensä tehdä töitä sen eteen, että hän saa toisen puhujan tuottamaan toisen kannanoton. Ensimmäinen puhuja on saattanut esimerkiksi kertoa pitkästi jostakin aiheesta, mutta kun toinen puhuja ei ole ottanut kantaa kuulemaansa, hän esittää itse ensimmäisen kannanoton ja 
kannustaa siten myös toista puhujaa esittämään kannanoton. Toinen kannanotto on siten usein aikaansaatu ja tavoiteltu (pursued) toiminto, jolle olisi ollut paikka jo aiemmin vuorovaikutuksessa.

\section{Toimintapyyntöihin vastaaminen}

Teoksen viides ja viimeinen analyysiluku käsittelee toimintapyyntöihin (request for action) vastaamista. Tämä kategoria sisältää myös direktiivit. Vastatessaan toimintapyyntöön amerikanenglannin puhujalla on käytettävissään kaikki muut vastauksen rakennetyypit paitsi lausekevastaukset, ja samaan tapaan kuin vastauksissa tiedonantoihin myös tässä kategoriassa partikkelivastaus on yleisin (40 partikkelivastausta yhteensä 92 esimerkin aineistossa). Partikkelivastaus on erityisesti toimintapyyntöön suostumista ilmaisevien vuorojen yleisin muoto, kun taas pyynnön kieltävissä vuoroissa tavataan eniten etujäsenen muodosta riippumattomia lausevastauksia (unrelated clausal). Toimintapyyntöön vastaamisessa tärkeiksi ulottuvuuksiksi nousevat Curlin ja Drew’n (2008) uraauurtavan tutkimuksen mukaisesti puhujien oikeudet (entitlement) ja pyynnön toteuttamiseen mahdollisesti liittyvät vaikeudet tai epävarmuudet (contingency).

Toimintapyyntöihin suostuvien vastausvuorojen yleisin muoto on partikkelivastaus (esim. Tell Keith Moon hello for me - Alright; Wesley would you ask the blessing - Alright; I want some of that mommy - Okay). Nähdäkseni merkittävää on, että tekijät eivät löydä systemaattista eroa muodoltaan erilaisten partikkelivastausten, kuten Alright, Okay ja Sure funktioiden väliltä. Sen sijaan he esittävät, että esimerkiksi mahdollisen vastahakoisuuden ilmaiseminen liittyy partikkelin tuottamisen ajoitukseen ja sen prosodiseen asuun. Myöntyvät partikkelivastaukset tuotetaan välittömästi pyynnön jälkeen tai osittain sen kanssa päällekkäin, mutta vastahakoi- nen tai jopa ironinen myöntyminen tuotetaan viipeellä ja sen prosodia saattaa olla korostettu (upgraded) suhteessa toimintapyyntöön: äänenvoimakkuus ja sävelkulun vaihteluväli saattavat olla suurempia kuin toimintapyynnössä.

Luvun lopussa tekijät esittävät vakuuttavan yhteenvedon, jossa toimintapyynnön esittämisessä sekä vastaamisessa keskeiseksi tekijäksi osoitetaan puhujien väliset deonttiset oikeudet. Kun pyyntö esitetään vahvalla deonttisella oikeutuksella (esim. Tell Keith Moon hello for me; I want some of that mommy), myöntyvän vastauksen rakennetyyppi on partikkeli. Toisaalta kun pyynnön esittäjän deonttiset oikeudet ovat pienemmät (esim. Please don't do X; Don't us do X please), myöntyvän vastauksen rakennetyyppi on partikkelia laajempi lausevastaus (esim. I won't; I'm not gonna do X). Kyseessä on tekijöiden mukaan deonttinen kongruenssi (Stevanovic \& Peräkylä 2012): Kun pyynnön esittäjällä on vahva oikeutus pyynnölle, pyynnön toteuttajan valitsema partikkelivastaus kongruoi pyynnön esittäjän oikeutuksen kanssa implikoimalla heikkoa deonttista kontrollia. Kun taas pyynnön esittäjän oikeutus pyynnön toteuttamiselle on heikompi, pyynnön toteuttajan lausevastaus implikoi vahvempaa deonttista kontrollia pyynnön toteuttamiseksi, jolloin jälleen saavutetaan kongruentti deonttinen suhde.

\section{Lopuksi}

Olen edellä esitellyt teoksen analyysilukujen keskeistä sisältöä. Teoksen lukuisiin mielenkiintoisiin ajatuksiin lukeutuu se havainto, että eri toimintakonteksteja vaikuttavat ohjaavan erilaiset vuorovaikutukselliset "moottorit". Vastauksissa kysymyssanan sisältäviin tiedonhakuihin ja tiedonantoihin sekvenssin kehittymistä ohjaa "episteeminen moottori" (Heritage 2012) - puhujien tavoitteena on tietämysten epäsymmetrian tasoittaminen. 
Vastauksissa kannanottoihin episteemisyydellä ei teoksen mukaan ole yhtä määräävää roolia, vaan puhujat tavoittelevat pikemminkin yksimielisyyttä (agreement) ja sitoutumisen symmetriaa. Vastauksissa toimintopyyntöihin sekvenssiä puolestaan ohjaa puhujien välisten deonttisten oikeuksien ja velvollisuuksien selvittäminen.

Teoksessa tarkasteltavien toimintakontekstien moninaisuuden vuoksi siinä päästään käsittelemään monia keskusteluntutkimuksessa viime vuosina pinnalla olleita teemoja, kuten episteemisyyttä (Heritage \& Raymond 2005; Stivers, Mondada \& Steensig 2011), deonttisuutta (Curl \& Drew 2008; Stevanovic \& Peräkylä 2012) sekä agentiivisuutta (Enfield 2011) vuorovaikutuksessa. Teos toimii siten myös ajantasaisena katsauksena keskustelunanalyysin kehitykseen.

Sen lisäksi, että tekijät esittävät oman, usein viimeaikaiseen tutkimukseen perustuvan näkemyksensä eri toimintakonteksteista, he tarkastelevat jokaisen analyysiluvun lopuksi vaihtoehtoisia selitystapoja. Esimerkiksi kysymyssanan sisältävään tiedonhakuun vastaamista voisi selittää preferenssin (Pomerantz 1984; Tainio 1997; Schegloff 2007), muotoon mukautumisen (type conformity, Raymond 2003) tai minimalisaation periaatteen (Levinson 1987) käsitteellä. Tekijät kuitenkin esittävät, että preferenssin käsite ei auttaisi näkemään eroa laajojen lausevastausten ja etujäsenen muodosta riippumattomien lausevastausten välillä, sillä molemmat olisivat preferoimattomia jälkijäseniä kysymyssanan sisältävälle tiedonhaulle; väite, että toinen muoto olisi vielä "preferoimattomampi" kuin toinen, ei auttaisi selittämään, miksi näin on. Samaan tapaan muotoon mukautumisen käsitteen mukaisesti voitaisiin analysoida, että sekä lausekevastaus että laaja lausevastaus tuottavat juuri sen tiedon, mitä kysymyssanan sisältävä tiedonhaku pyysi (Schegloff 2007). Tällöin ei kuitenkaan pystyttäisi selittämään muo- tojen välisiä funktionaalisia eroja, kuten tekijät osoittavat. Minimalisaation periaatteen taas voisi nähdä selittävän, miksi lausekevastaukset ovat yleisin vastaustyyppi tarkennusta hakevan tiedonhaun jälkeen. Tällöin jäisi kuitenkin selittämättä, miksi lausekevastaus on "preferoimaton" toiminto kerrontaa hakevan tiedonhaun jälkeen. Edellä luetelluista syistä tekijät päätyvät siihen, että heidän valitsemansa selitystapa kysymyssanan sisältäviin tiedohakuihin vastaamisesta on osuvin ja perustelluin.

Thompsonin, Foxin ja Couper-Kuhlenin teos tarjoaa vuorovaikutuksentutkijoille siis kattavan katsauksen tieteenalan nykytilaan ja kiinnostuksen kohteisiin. Se on kuitenkin muutakin kuin tieteenalan nykytilannetta yhteenvetävä katsaus. Esitetty analyysi yhdistää kekseliäällä tavalla aiemmissa tutkimuksissa tehtyjä havaintoja yhdeksi näkemykseksi, minkä lisäksi analyysi yltää uusiin, vakuuttaviin tapoihin tulkita sosiaalista toimintaa. Tuloksena on aiempaa tarkempi ja rikkaampi käsitys niistä tekijöistä, jotka vaikuttavat responssien muotoiluun erilaisissa tilanteissa. Teoksen keskeisiin tuloksiin kuuluu myös sen osoittaminen, että prosodia on usein vähintään yhtä keskeinen tekijä kuin syntaksi etsittäessä selityksiä eri tavoin muotoiltujen vuorojen funktioille. Toisaalta prosodisen tarkastelun painotus esimerkiksi kannanottosekvenssejä tarkasteltaessa jättää ajoittain kuvan, että syntaksin tarkastelulle ei välttämättä jäänyt tarpeeksi tilaa. Näiden kahden aspektin, prosodian ja syntaksin, yhtäaikainen ja tasapainoinen huomiointi on vaikea tehtävä, joka vaatii tutkijoilta monipuolista osaamista. Teoksessa tehty ratkaisu, kolmen tekijän yhteistyö, mahdollistaa paitsi useiden toimintakontekstien tarkastelun myös eri tutkijoiden erityisosaamisen optimaalisen hyödyntämisen.

JARKKO NIEMI etunimi.j.sukunimi@helsinki.fi 


\section{Lähteet}

Curl, Traci S. - Drew, Paul 2008: Contingency and action. A comparison of two forms of requesting. - Research on Language and Social Interaction $41 \mathrm{~s}$. 129-153.

ENFIELD, NiCK 2011: Sources of asymmetry in human interaction. Enchrony, status, knowledge, and agency. - Tanya Stivers, Lorenza Mondada \& Jakob Steensig (toim.), The morality of knowledge in conversation s. 285-312. Cambridge: Cambridge University Press.

Goodwin, Charles - Goodwin, Marjorie H. 1992: Assessments and the construction of context. - Charles Goodwin \& Alessandro Duranti (toim.), Rethinking context s. 147-189. Cambridge: Cambridge University Press.

Haddington, Pentti 2006: The organization of gaze and assessments as resources for stance taking. - Text \& Talk $26 \mathrm{~s}$. 281-328.

Hakulinen, Auli - Sorjonen, MarjaLEENA 2009: Designing utterances for action. Verb-repeat responses to assessments. - Markku Haakana, Minna Laakso \& Jan Lindström (toim.), Talk in interaction. Comparative dimensions $\mathrm{s}$. 124-151. Helsinki: Suomalaisen Kirjallisuuden Seura.

Heritage, John 1984: A change-of-state token and aspects of its sequential placement. - J. Maxwell Atkinson \& John Heritage (toim.), Structures of social action. Studies in conversation analysis s. 299-345. Cambridge: Cambridge University Press.

- 2012: The epistemic engine. Sequence organization and territories of knowledge. - Research on Language and Social Interaction 45 s. 30-52.

Heritage, John - Raymond, Geoffrey 2005: The terms of agreement. Indexing epistemic authority and subordination in talk-in-interaction. - Social Psychology
Quarterly 68 s. 15-38.

JefFerson, Gail 1981: The abominable 'ne'? An exploration of post-response pursuit of response. - Peter Schröder \& Hugo Steger (toim.), Sprache der Gegenwaart s. 53-88. Dusseldorf: BRD Pedagogischer Verlag Schwann.

Koivisto, Aino 2015: Displaying nowunderstanding. The Finnish change-ofstate token aa. - Discourse Processes 52 s. 111-148.

_ 2016. Receipting information as newsworthy vs. responding to redirection. Finnish news receipts aijaa and $a h a(a)$. - Journal of Pragmatics 104 s. 163-179.

Levinson, Stephen 1987: Minimization and conversational inference. - Marcella Bertuccelli Papi \& Jef Verschueren (toim.), The pragmatic perspective. Selected papers from the 1985 International Pragmatics Conference s. 61-130. Amsterdam: John Benjamins.

Niemi, JARKko 2013: Tiedon rajat ja vuorovaikutus. Toteamukseen tai vaihtoehtokysymykseen vastaavat voI OLLA -rakenteet. - Virittäjä 117 s. 201-241.

Ogden, Richard 2006: Phonetics and social action in agreements and disagreements. - Journal of Pragmatics $38 \mathrm{~s}$. 1752-1775.

Pomerantz, Anita 1984: Agreeing and disagreeing with assessments. Some features of preferred/dispreferred turn shapes. - J. Maxwell Atkinson \& John Heritage (toim.), Structures of social action. Studies in conversation analysis $\mathrm{s}$. 57-101. Cambridge: Cambridge University Press.

Raymond, Geoffrey 2003: Grammar and social organization. Yes-no interrogatives and the structure of responding. - American Sociological Review $68 \mathrm{~s}$. 939-967.

Schegloff, Emanuel A. 1996: Turnorganization. One direction for inquiry into grammar and interaction. - Elinor Ochs, Emanuel A. Schegloff \& Sandra A. 
Thompson (toim.), Interaction and grammar s. 52-133. Cambridge: Cambridge University Press.

- 2007. Sequence organization in interaction. A primer in conversation analysis. Volume 1. Cambridge: Cambridge University Press.

Stevanovic, Melisa - Peräkylä, Anssi 2012: Deontic authority in interaction. The rights to announce, propose, and decide. - Research on Language and Social Interaction 45 s. 297-321.

Stivers, TAnya 2005: Modified repeats. One method for asserting primary rights from second position. - Research on Language and Social Interaction $38 \mathrm{~s}$. 131-158.

Stivers, Tanya - Mondada, Lorenza

- Stennsig, Jakob 2011: Knowledge, morality and affiliation in social interaction. - Tanya Stivers, Lorenza Mondada \& Jakob Steensig (toim.), The morality of knowledge in conversation s. 3-26. Cambridge: Cambridge University Press.

TAinio, LiIs A 1996: Kannanotoista arkikeskustelussa. - Auli Hakulinen (toim.), Suomalaisen keskustelun keinoja II s. 81-103. Kieli 10. Helsingin yliopiston suomen kielen laitos.

— 1997: Preferenssijäsennys. - Liisa Tainio (toim.), Keskustelunanalyysin perusteet $\mathrm{s}$. 93-110. Tampere: Vastapaino.

Tomasello, Michael 2008. Origins of human communications. Cambridge: MIT Press.

\section{Kauan eläköön suomi!}

Lari Kotilainen: Kielen elämä. Suomen kieli eilisestä huomiseen. Helsinki: Siltala 2016. 239 s. ISBN 978-952-234-367-3.

Lari Kotilainen tunnetaan suomen kielen tutkijana, akateemisena opettajana ja kielen sekatyöläisenä, joka kirjoittaa blogia nimimerkillä Suomensuojelija (ks. http://www.suomensuojelija.fi). Aiemmin hän on julkaissut samannimisen teoksen, jonka alaotsikkona on Ohjekirja kielen pelastamiseen (ks. Kotilainen 2009). Lukijan ei siis uutta teosta avatessaan tarvitse arvailla, mikä on Kotilaisen suhde ja asenne suomen kieleen. Hän tekee työtä sen hyväksi sekä tosissaan että leikillisesti. Tämän arvostelun otsikko on lainattu teoksen ensimmäiseltä luvulta.

Kielen elämä on rennolla otteella kirjoitettu suomen kielen elämäkerta. Se lähtee liikkeelle tuhansien vuosien takaa kantauralista ja päätyy kurkistamaan nykyhetkestä muutaman kymmenen vuoden päässä odottavaan tulevaisuuteen. Aikamatka ei kuitenkaan jakaudu tasaisesti eri kehityskausien osalle. Kaikki esikristilliset vuosituhannet on kuitattu 16 sivulla, ja suunnilleen samanmittainen on suomen kielen esikirjallisten vaiheiden osuus ajanlaskun alusta reformaation kynnykselle. Agricolalle ja suomen kirjakielen synnylle on omistettu parikymmentä sivua. Se on hieman enemmän kuin on saanut osakseen koko Ruotsin ajan loppupuoli Agricolasta eteenpäin. Sitten repeää: 180o-luvun kehitystä käsittelevä osuus on peräti 67 sivun mittainen. 1900-lukuun keskittyvä "Suomi voimainsa tunnossa" on taas yllättävän lyhyt, niukat 17 sivua. Kirjan neljässä viimeisessä luvussa Kotilainen tutkailee 200o-luvun nykyisyyttä ja tulevaisuutta yhteensä 59 sivun verran. Lo- 